\title{
Hypertriglyceridemia in female rats during pregnancy induces obesity in male offspring via altering hypothalamic leptin signaling
}

\author{
Tanzil Ur Rahman ${ }^{1,2, *}$, Kamran Ullah ${ }^{1,2, *}$, Zhang-Hong Ke ${ }^{4}$, Meng-Xi Guo ${ }^{1,2}$, Lu-Yang \\ Jinn $^{1,2}$, Jun Ren ${ }^{1,2}$, Yu-Zhong Zhou ${ }^{1,2}$, Yi Cheng ${ }^{1,2}$, Xin-Yan Dong ${ }^{1,2}$, Hai-Yan Pang ${ }^{1,2}$, \\ Ting-Ting Wang ${ }^{1}$, Jian-Zhong Sheng ${ }^{1,2,3}$ and He-Feng Huang ${ }^{1,3}$ \\ ${ }^{1}$ The Key Laboratory of Reproductive Genetics, Ministry of Education, Zhejiang University, Hangzhou, China \\ ${ }^{2}$ Department of Pathology and Pathophysiology, School of Medicine, Zhejiang University, Hangzhou, China \\ ${ }^{3}$ The International Peace Maternity and Child Health Hospital, School of Medicine, Shanghai Jiao Tong University, Shanghai, \\ China \\ ${ }^{4}$ Center of Reproductive Medicine, Fujian Maternity and Children Health Hospital, Fujian Medical University, Fuzhou, China \\ *These authors have contributed equally to this work
}

Correspondence to: Jian-Zhong Sheng, email: shengjz@zju.edu.cn He-Feng Huang, email: huanghefg@hotmail.com

Keywords: triglyceridemia, leptin, hypothalamus, neuropeptide Y, PSTAT3

Received: February 08, 2017

Accepted: May 10, 2017

Published: June 16, 2017

Copyright: Rahman et al. This is an open-access article distributed under the terms of the Creative Commons Attribution License 3.0 (CC BY 3.0), which permits unrestricted use, distribution, and reproduction in any medium, provided the original author and source are credited.

\section{ABSTRACT}

Maternal obesity influence the child's long-term development and health. Though, the mechanism concerned in this process is still uncertain. In the present study, we explored whether overfeeding of a high-fat diet during pregnancy in female rats altered metabolic phenotypes in an F1 generation and authenticated the contribution of hypothalamic leptin signaling. Leptin responsiveness and the number of immunopositive neurons for phosphorylated signal transducer and activator transcription 3 (pSTAT3) were analyzed. Neuropeptide $Y$ in the arcuate nucleus of the hypothalamus and in nucleus tractus solitaries was examined. Triglycerides and leptin levels were increased in the high-fat diet mother. The number of neuropeptide $Y$ positive cell bodies and neurons was significantly increased in the high-fat diet-F1 offspring (HDF-F1) as compared to Chow-F1. Leptin administration significantly decreased the food intake and increased the PSTAT3 expression levels in neurons in the arcuate nucleus of Chow-F1. However, leptin did not show any effect on food intake and had a reduced effect on PSTAT3 expression levels in neurons in the arcuate nucleus of HDF-F1. From the present domino effect, we conclude that mothers exposed to high-fat diet during pregnancy may pass the obese phenotype to the succeeding generation via altering hypothalamic leptin signaling.

\section{INTRODUCTION}

Obesity is global health alarm and its frequency in adults and children is growing dramatically. Women with a high body mass index (BMI) are most likely susceptible to pregnancy complications and adverse perinatal outcomes including diabetes, hyperlipidemia, cardiovascular diseases, and numerous other problems $[1,2]$. In the United States, one-third of women are obese and two-third are overweight [3]. In china, the proportion of overweight children and teenagers are $19.4 \%$ and $5.8 \%$ are obese [4]. Research on different animal models revealed that HFD induced obesity and other metabolic disorders in their offspring $[5,6]$. Moreover, maternal obesity is accountable 
for the direct transmission of obesogenic and diabetogenic phenotypes to the succeeding generation, but the exact mechanism is not fully understood.

The arcuate center (Arc) in the hypothalamus is a key area of leptin signaling [7, 8]. Peripheral leptin is transported transversely the blood-brain barrier (BBB) near to circumventricular organs to stimulate leptin receptor [9]. It has been reported that obesity and overnutrition modified the central leptin sensitivity [10] and appetitecontrolling signals $[6,11]$. These observations indicated that maternal obesity-programmed the brain development of their offspring, but the areas related to food intake and energy homeostasis has not been entirely explored.

Rodents increased their food ingestions, fat deposition, and insulin resistance during gestation [12, 13]. These features look like the metabolic adaptive conditions that cause obesity, for example, prolonged HFD feeding [14]. Remarkably, leptin sensitivity is a hallmark of both gestation and HFD feeding $[15,16]$. Hence, leptin resistance could denote a crucial factor tangled in the metabolic alterations perceived during pregnancy.

Leptin, an adipocytes hormone, reduced food intake by binding to its receptor and then modifying the excitation of neurons in the Arc and nucleus tractus solitaries (NTS) in the brainstem $[17,18]$. The Arc carries two major clusters of neurons that respond to leptin concentrations: pro-opiomelanocortin neurons (POMC) and neuropeptide Y (NPY) neurons. Anorexigenic peptides are articulated by POMC while orexigenic peptides are expressed by NPY $[19,20]$. Leptin drops energy intake and body weight through pSTAT3 signaling pathway. Leptin phosphorylate and activate STAT3, afterward upregulates the gene encoding POMC and decreased NPY expression, and finally leads to a decrease in food consumption and body mass $[21,22]$. Though most heavy humans and rodents have increased levels of circulating leptin, and despite leptin resistance, the high leptin levels have no effects on appetite and energy outflow [23].

The majority of research works were performed on males; it would be exciting to determine whether HFD feeding during pregnancy in female rats predispose obesity in their male offspring. We, therefore, asked a question, whether HFD feeding during pregnancy in female rats could alter feeding circuits and produce adiposity in male offspring and conclusive efforts may clarify the bottom line mechanism in the hypothalamus.

\section{RESULTS}

\section{High maternal triglyceride (TG) levels are associated with persistent elevations in leptin levels}

To explore the effects of mTG on leptin levels in male offspring, we first investigated serum TG levels and leptin levels in both control mothers (Chow-P1) and high- fat diet mothers (HFD-P1). Serum TG and leptin levels in HFD-P1 rats were significantly increased than in controls (Figure 1A, 1B). On the other hand, the area of adipocytes was also significantly increased in HFD-P1 (Figure 1C). Moreover, we found that serum leptin concentration was also significantly increased in HFD-F1 offspring (Figure 1D) than that in Chow-F1 offspring. Figure 1E represents adipocyte photomicrographs of control and HFD mothers. These results revealed that maternal hypertriglyceridemia was associated with significantly increased leptin levels in their offspring.

\section{HFD feeding during pregnancy affects body mass, hyperphagia, and fat distribution}

To perceive whether maternal obesity-induced by HFD feeding during pregnancy in rat impact on the attaining body weight and developmental growth rate of their male offspring. The early body weight was the same between two groups. Later, HFD-F1 became heavier than the Chow-F1 up to day 29 (Figure 2A, 2B). Figure $2 \mathrm{C}$ represents adipocytes of Chow-F1 and HFD-F1. The weight of white adipose tissue on epididymis, body length, and adipocyte size were significantly increased in the HFD-F1 offspring (Figure 2D, 2E, 2F). At day 21 the male offspring were placed on solid chow diet and daily food intake was measured from day 21 to day 30. Daily food consumption by HFD-F1 was higher than Chow-F1 (Figure 2G). Blood glucose (Glu), total cholesterol (TC), low-density lipoproteins (LDL) and high-density lipoproteins (HDL) concentrations did not vary between HFD-F1 and Chow-F1 (Table 1). These data shows that maternal obesity as a result of HFD overfeeding during pregnancy induced significant adiposity possibly via an increased excitation of feeding circuits.

\section{HFD feeding during pregnancy displayed perverted neuronal feeding circuit}

Both POMC and NPY are hypothalamic peptides, and their expressions are increased and decreased by leptin signaling, respectively. Leptin signaling in the hypothalamus is negatively regulated by Suppressor of cytokine signaling 3 (SOCS3). To figure out if the hyperphagia of HFD-F1 was associated with these factors, we performed quantitative real-time PCR. NPY (Figure 3A) and SOCS3 mRNA levels (Figure 3E) of HFD-F1 (4 weeks old) were up-regulated, whereas POMC (Figure 3C) and the leptin receptor mRNA levels (ObRb) (Figure 3G) remains unchanged in both groups. Western blot analysis of hypothalamic protein extracts showed that HFD-F1 had increased NPY (Figure 3B) and SOCS3 (Figure 3F) levels than Chow-F1, while POMC (Figure 3D) and ObRb (Figure 3H) were not altered. 


\section{HFD feeding during pregnancy displayed increased orexigenic NPY expression}

To further evaluate the NPY-immunoreactivity (IR) in the Arc and NTS, immunofluorescence was performed. Figure 4A indicates the area of NPY-IR cell bodies in the Arc. Each solid circle represents NPY-IR cell bodies. Arc and NTS from HFD-F1 displayed a significantly increased number of NPY positive neurons (Figure 4C, 4F) than Chow-F1 (Figure 4B, 4E). Figure 4D, 4G signifies the negative control. Arrowhead represents the neuronal cell bodies in the Arc and NTS. Quantitative analysis showed that HFD-F1 had significantly increased the number of positive neurons in both Arc and NTS nuclei (Figure 4H,
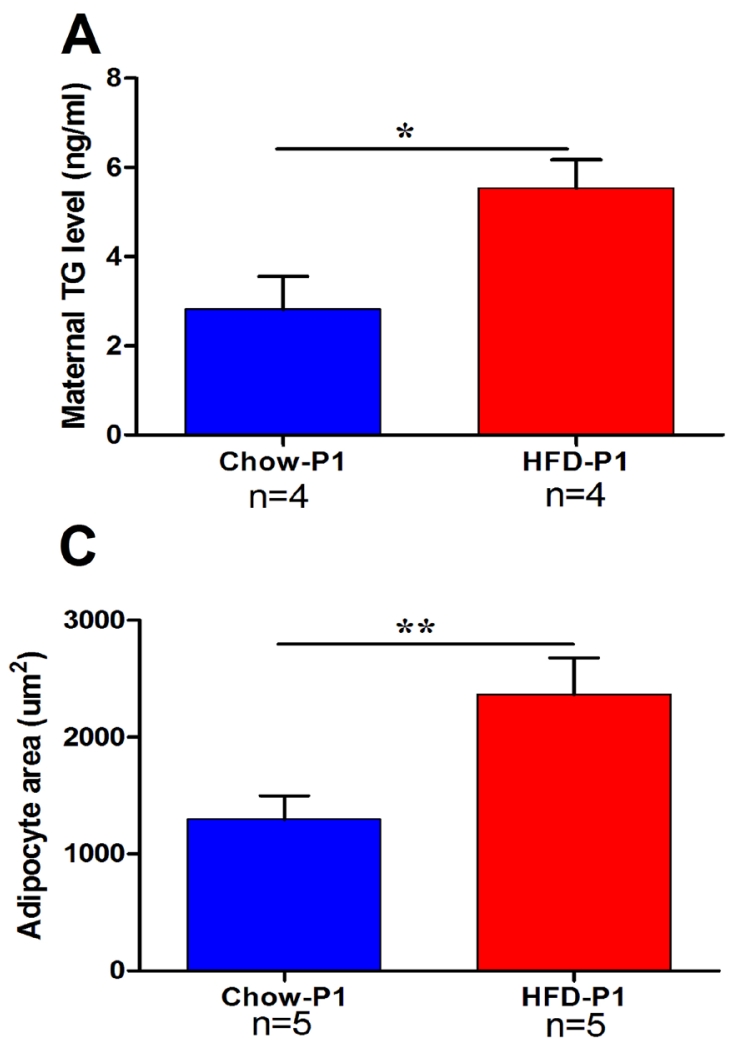

E

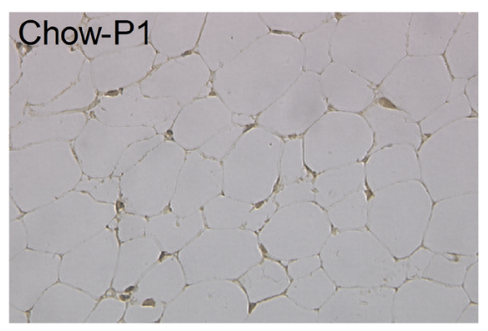

4I). Immunohistochemical (IHC) analysis also showed the increased number of NPY-IR neuronal bodies in Arc and NTS of HFD-F1 offspring than Chow-F1 (Supplementary Figure 1). For more validation, we extracted protein from Arc and NTS and performed western blot analysis. Figure 4J, 4K shows that NPY protein concentrations in Chow-F1 Arc and NTS were significantly decreased as compared to HFD-F1.

\section{HFD feeding during pregnancy induced significant leptin resistance}

To investigate if the hyperphagia of HFD-F1 is linked with leptin sensitivity in the hypothalamus, both
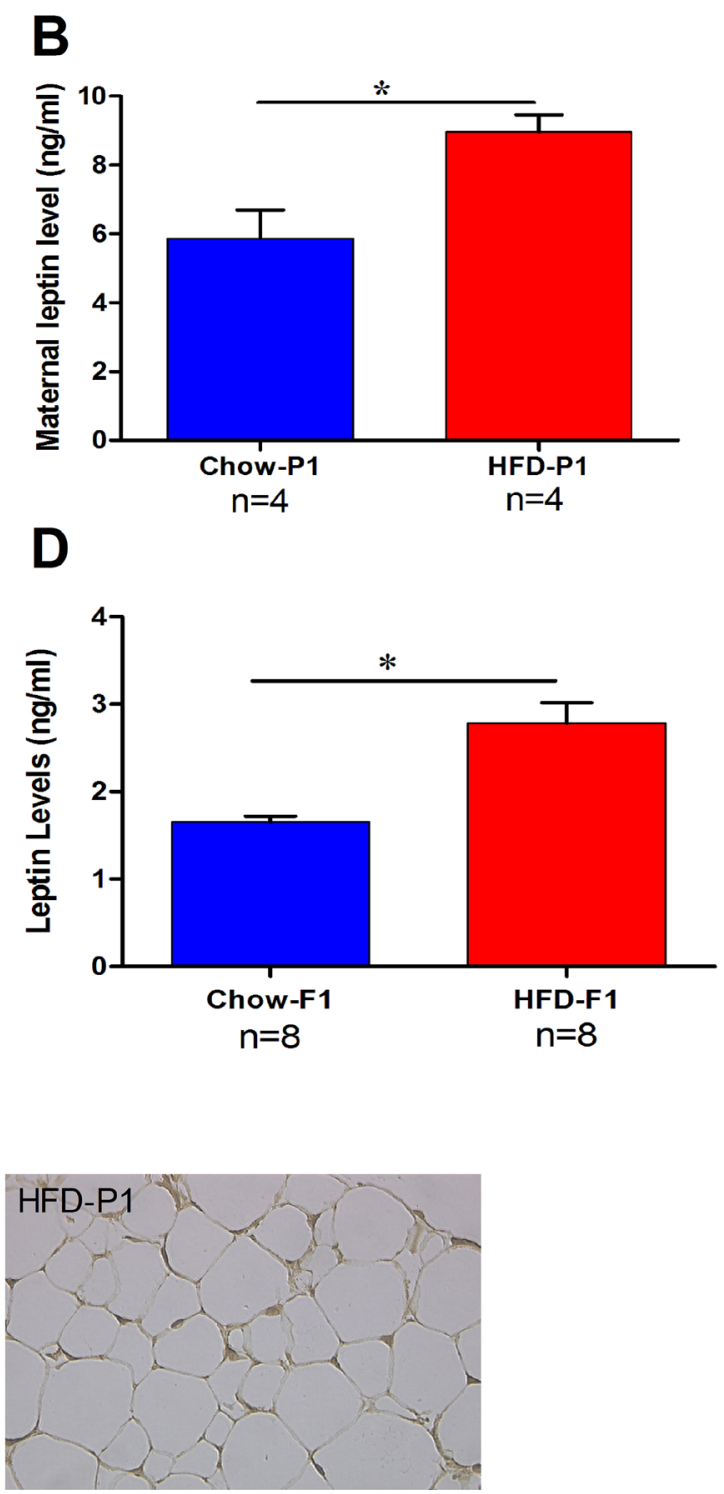

Figure 1: High maternal TG levels are linked with persistent elevations in male offspring leptin levels. (A) TG levels in Chow and HFD mothers. (B) Serum leptin levels in Chow and HFD mother. (C) Adipocyte areas of the ovary fat pad of Chow and HFD mother. (D) Serum leptin levels of Chow-F1 and HFD-F1 offspring. (E) Representative photomicrographs of Chow and HFD mothers adipocytes. Results expressed as means \pm SEM and the differences between the two groups were analyzed with Student's t-test. ${ }^{*} p<0.05$, $* * p<0.01$. 
food intake and quantification of pSTAT3-IR in Arc were achieved. In Chow-F1, leptin administration $(2 \mu \mathrm{g} / \mathrm{g})$ lowered food intake at 1, 2, 6 and $12 \mathrm{~h}$ subsequently. On another side, leptin injection has no significant effect on food intake in HFD-F1, suggesting that HFD-F1 might have leptin resistance (Figure 5A). On day 30, pSTAT3IR neurons were very few or even invisible in the ChowF1-S and HFD-F1-S groups (Figure 5B, 5E). After leptin injection, the Chow-F1 showed significantly increased

A

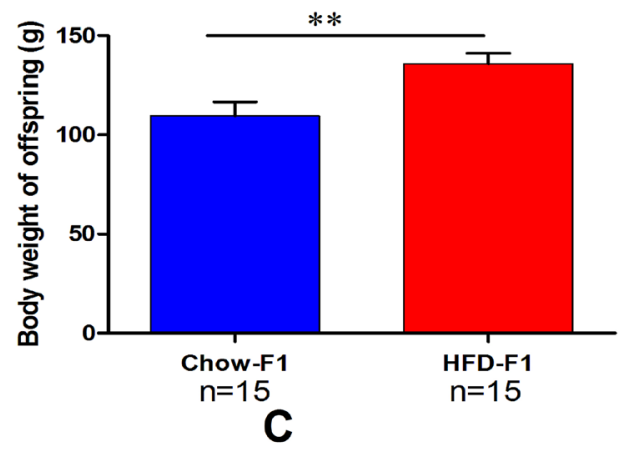

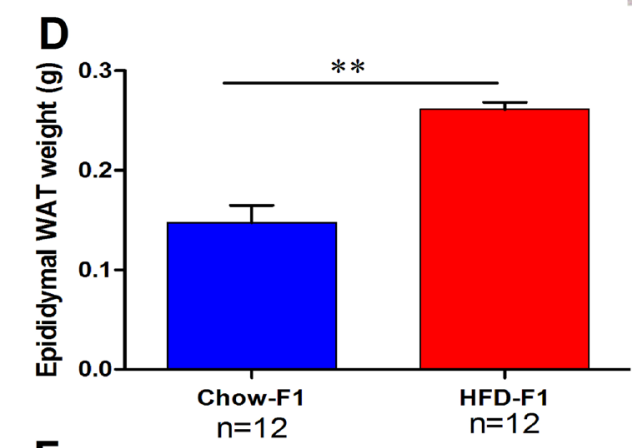
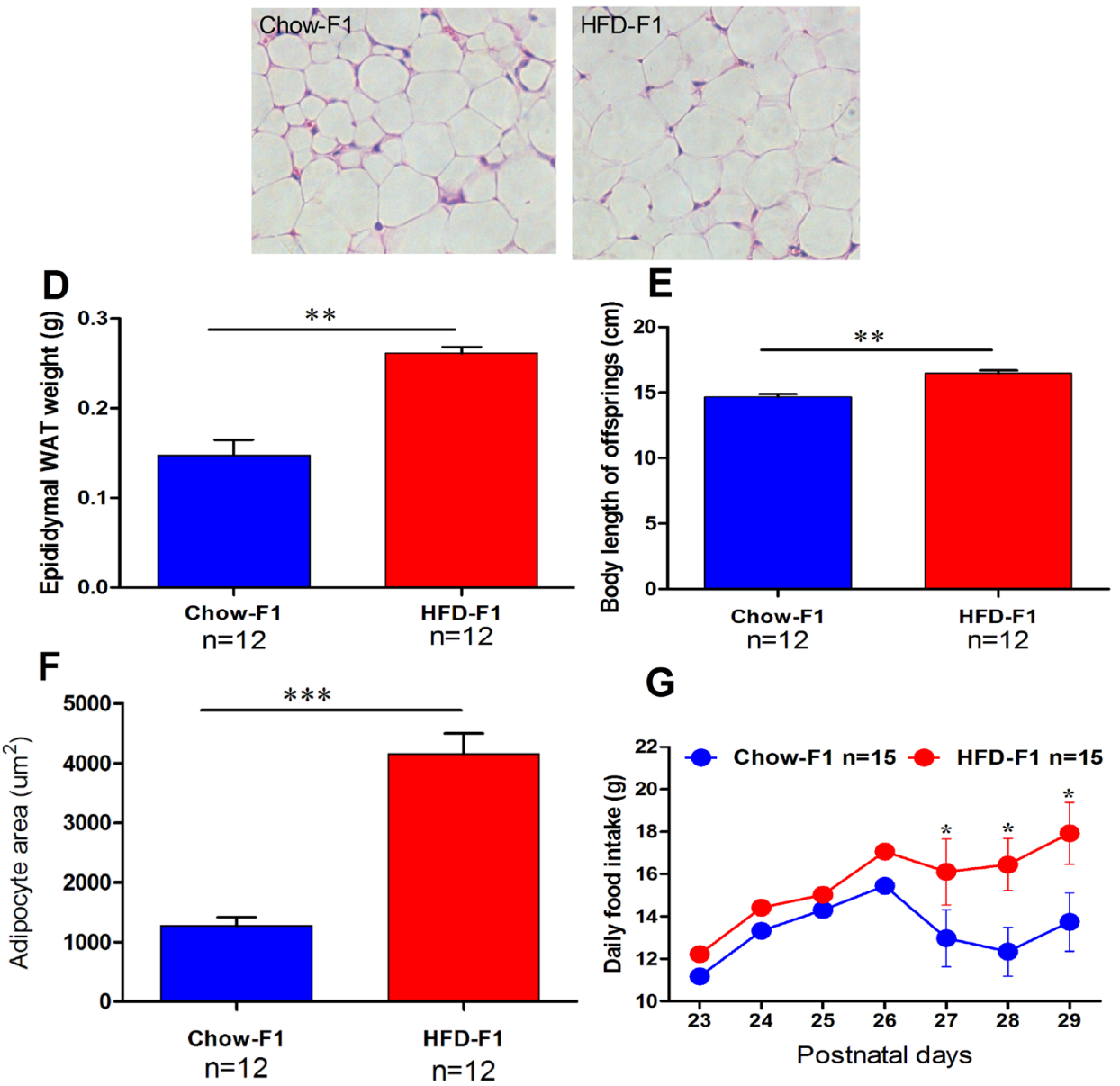

G

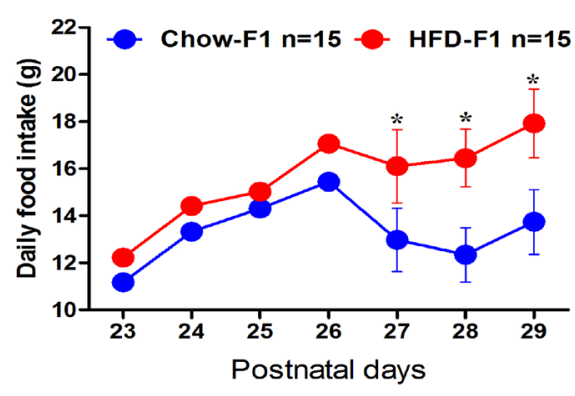

Figure 2: HFD feeding during pregnancy in female rats induced rapid weight gain, hyperphagia, and adiposity in male offspring. (A) Body weight changes of Chow-F1 and HFD-F1 from postnatal day P0 to P28. (B-C) Representative photomicrographs of Chow-F1 and HFD-F1 offspring and adipocytes. (D-E) The Weight of epididymal WAT and body length of Chow-F1 and HFD F1. (F-G) Adipocytes area and daily food intake from P23 to P29. The data are expressed as the mean \pm SEM and the differences between the two groups were analyzed with Student's t-test. ${ }^{*} p<0.05, * * p<0.01, * * * p<0.001$. 
Table 1: Blood biochemical indices in male Chow-F1 and HFD-F1 offspring

\begin{tabular}{lccccc}
\hline & & Glucose $(\mathbf{m M})$ & HDL $(\mathbf{m M})$ & LDL $(\mathbf{m M})$ & TC $(\mathbf{m M})$ \\
\hline Chow-F1 & $\mathrm{n}=8$ & $7.8 \pm 0.37$ & $0.80 \pm 0.06$ & $0.78 \pm 0.01$ & $2.35 \pm 0.09$ \\
HFD-F1 & $\mathrm{n}=8$ & $7.9 \pm 0.51$ & $0.78 \pm 0.06$ & $0.76 \pm 0.07$ & $2.26 \pm 0.10$ \\
\hline
\end{tabular}

Data were presented as the mean \pm SEM. Glucose levels were measured using a glucometer. High-density lipoprotein, low density lipoprotein and total cholesterol were measured with a biochemical analyzer (Advia 2400 Chemistry System).

A

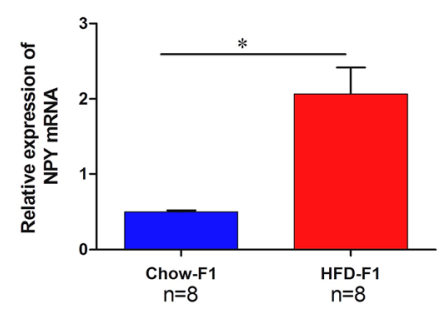

C

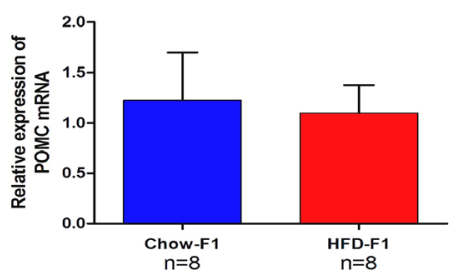

E

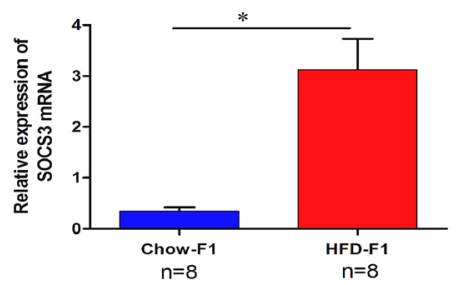

G

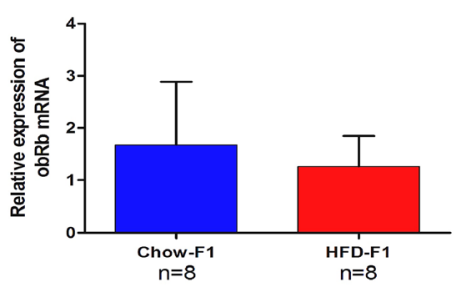

B

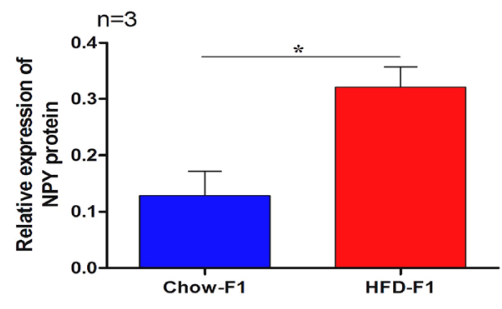

D

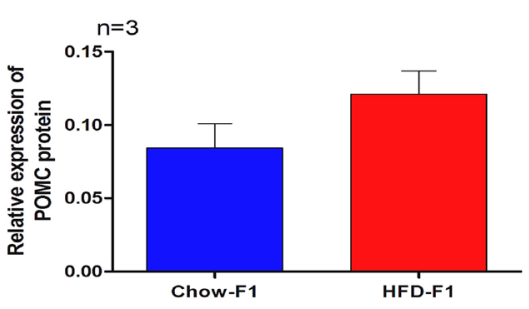

F

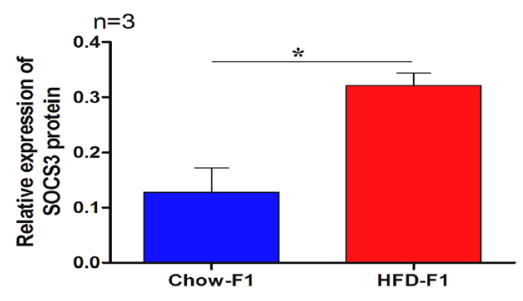

H

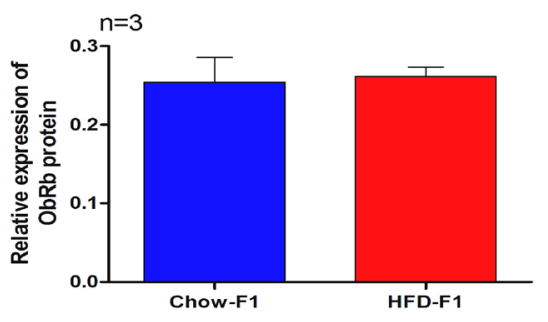

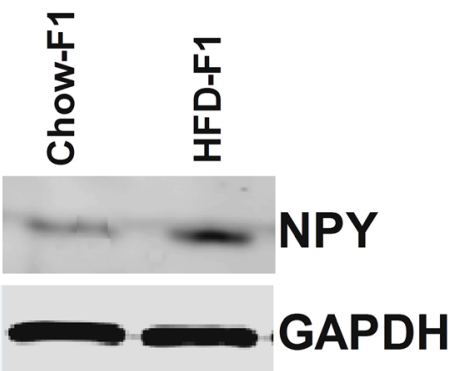

$\begin{array}{ll}\frac{5}{4} & \text { ㄴ. } \\ 3 & \frac{0}{0}\end{array}$

POMC

GAPDH
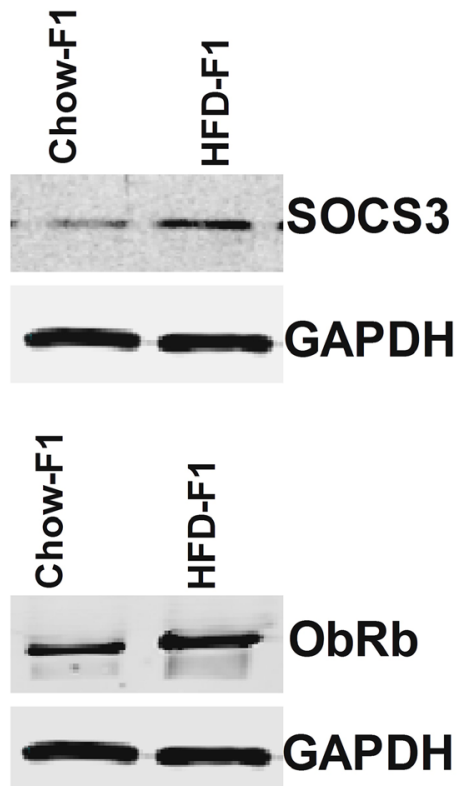

Figure 3: Effect of HFD overfeeding during pregnancy in female rats alters male hypothalamic feeding circuit genes. The mRNA levels in the hypothalamus of Chow-F1 and HFD-F1 were determined by a quantitative real-time polymerase chain reaction and protein quantification by western blot. (A-B) Relative mRNA expression and proteins levels of NPY. (C-D) Relative mRNA expression and protein levels of POMC. (E-F) Relative mRNA expression and protein levels of SOCS3. (G-H) Relative mRNA expression and protein levels of $\mathrm{ObRb}$. Values are expressed as the mean $\pm \mathrm{SEM}$ and analyzed with Student's t-test. ${ }^{*} p<0.05$. 
A

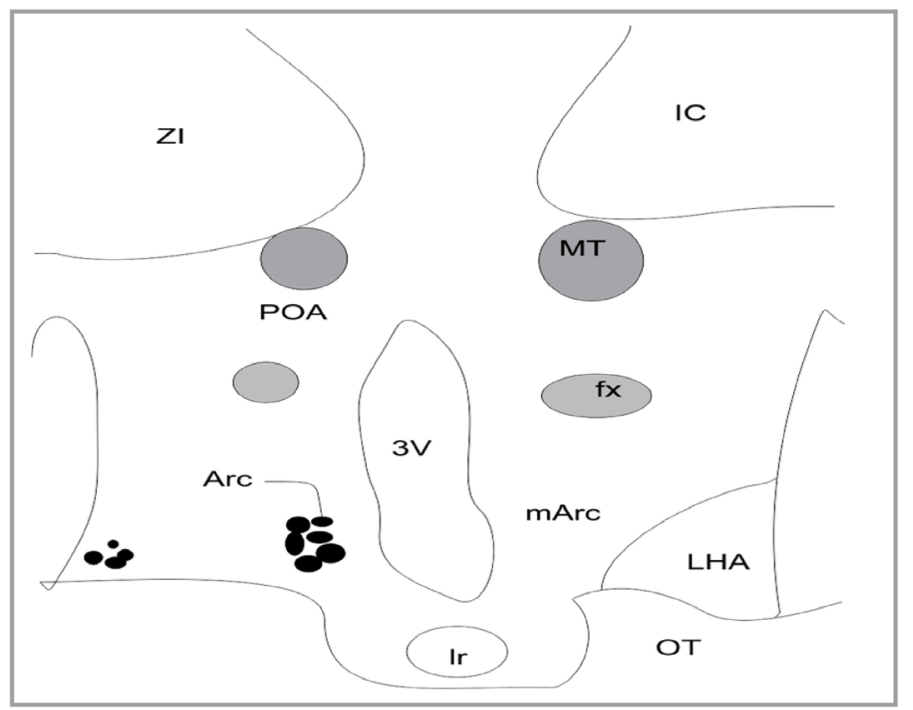

H
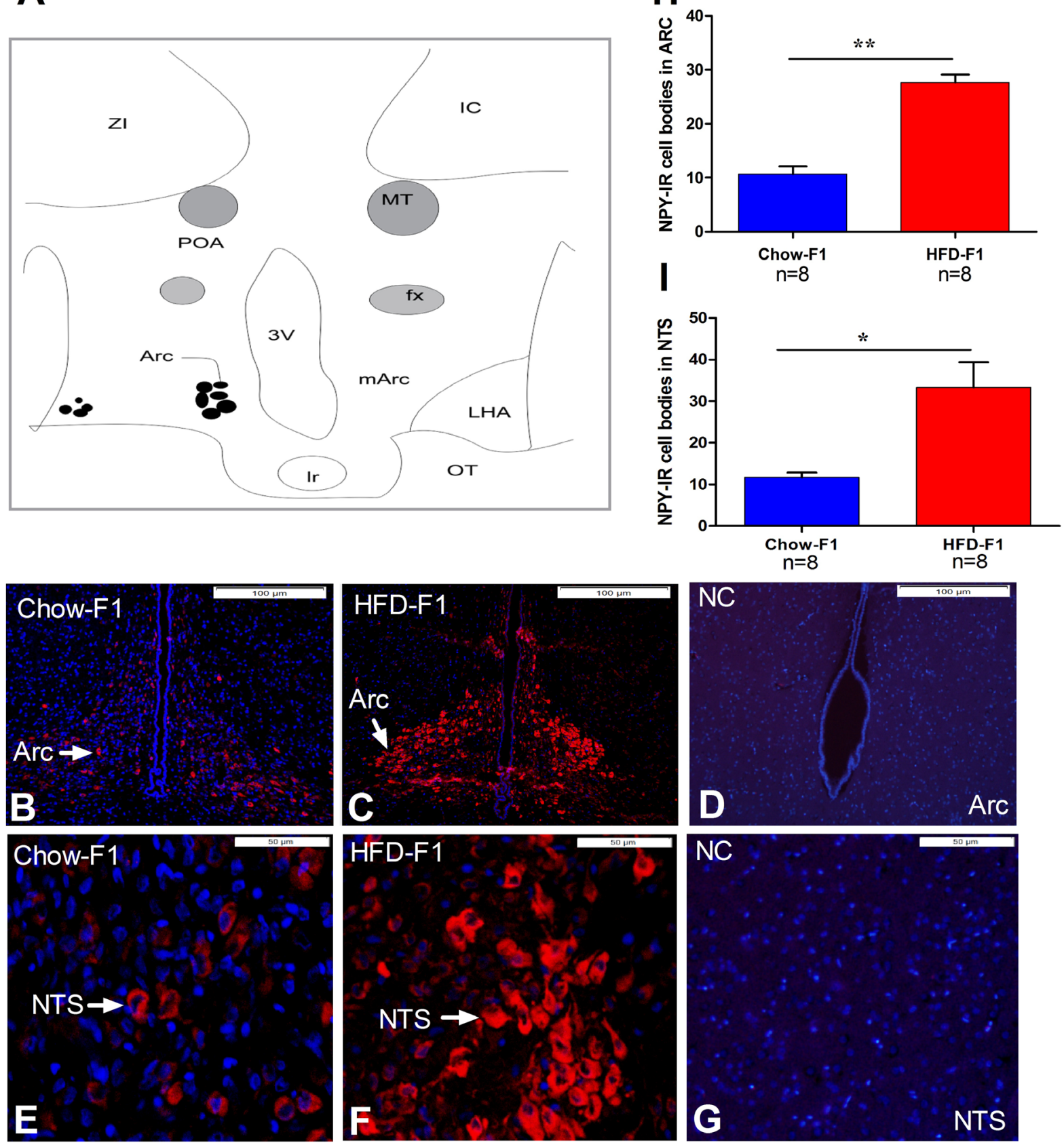

$\mathbf{J}$

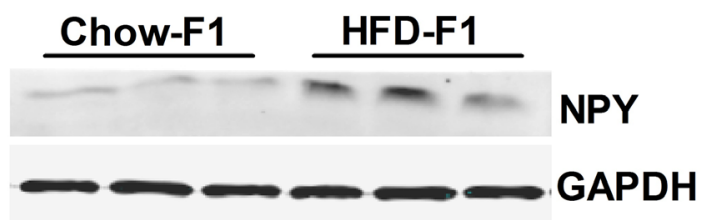

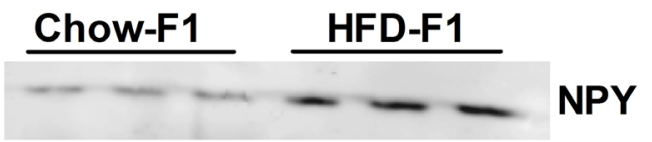

GAPDH

Figure 4: NPY expression in the hypothalamus and brain stem. (A) Each solid circle represents NPY-IR cells. POA, preoptic area; OC, optic chiasm; fx, fornix; ZI, zona incerta; mARC, middle arcuate; LHA, lateral hypothalamic area; OT, optic tract; 3V, 3rd ventricle; IC, internal capsule; mt, mammillary tract. (B-C) NPY expression in the Arc of Chow-F1 and HFD-F1. (E-F) NPY expression in the NTS of Chow-F1 and HFD-F1. (D-G) Represents the negative control (NG) for Arc and NTS. (H-I) Quantitative results of NPY positive neurons in the Arc and NTS. (J-K) Western blot analysis of NPY protein from Arc and NTS. Loading was normalized using GAPDH. The data are expressed as the mean $\pm \mathrm{SEM}$ and the differences between the two groups were analyzed with Student's t-test. ${ }^{*} p<0.05,{ }^{*} p<0.01$. 

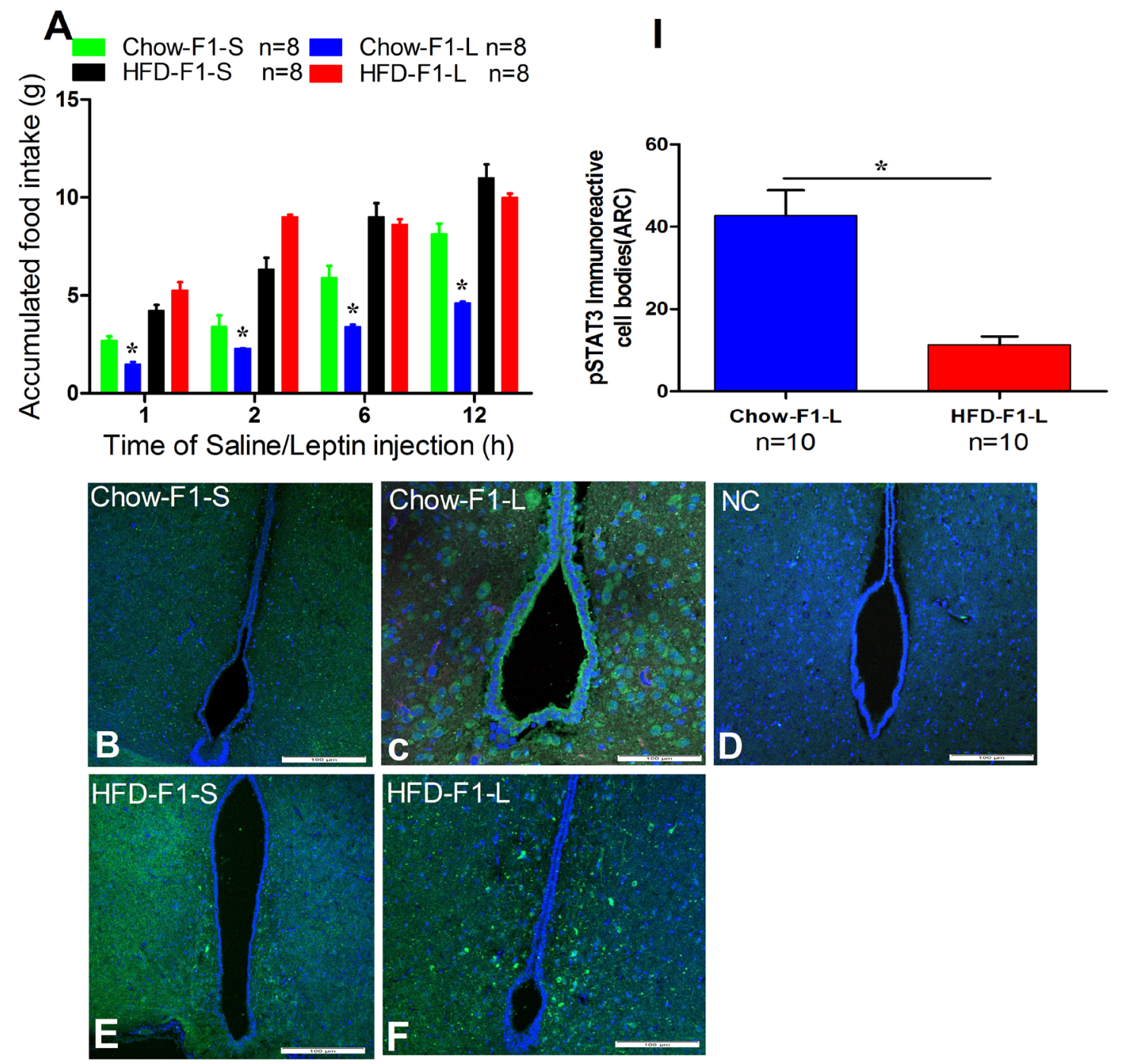

\section{G}
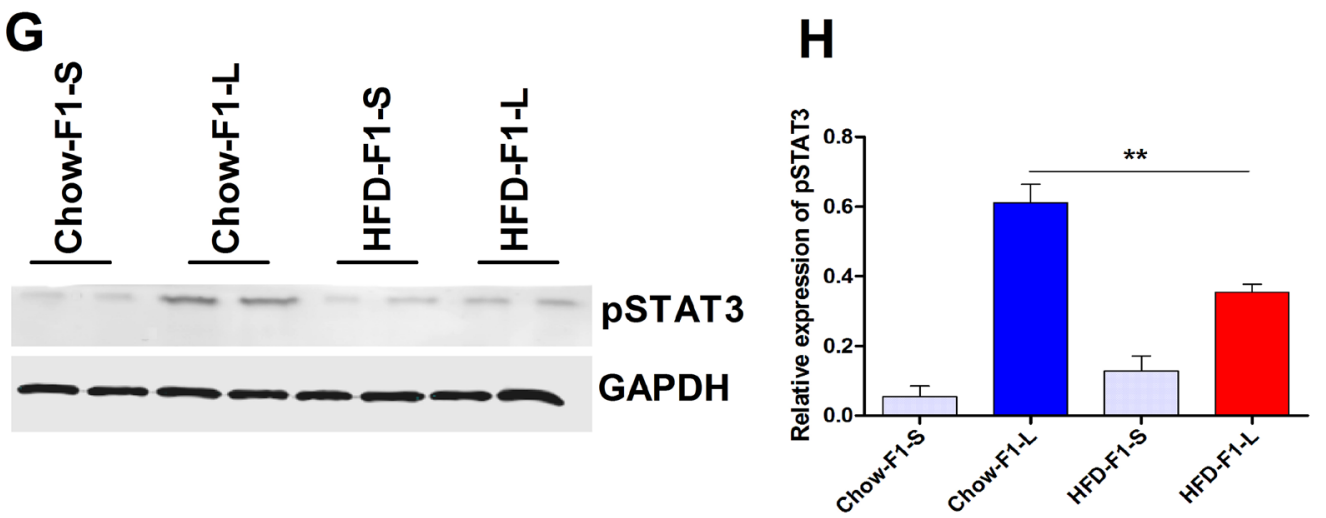

Figure 5: HFD overfeeding during pregnancy in female rats induced leptin resistance in male offspring. Using a twoway ANOVA, food intake values at four-time points were found to be significantly lower in Chow-F1 treated with leptin compared to all other groups. ${ }^{*} P<0.05$. (A) Food intake 1, 2, 6 and $12 \mathrm{~h}$ after i.p. leptin $(2 \mu \mathrm{g} / \mathrm{g}) / \mathrm{saline}$. (B) Expression of pSTAT3 in Chow-F1 after saline injection. (C) Expression of pSTAT3 in Chow-F1 after leptin injection. (D) Represents the negative control (NC). (E) Expression of pSTAT3 in HFD-F1 after saline injection. (F) Expression of pSTAT3 in HFD-F1 after leptin injection. (G-H) Western blot analysis of pSTAT3 after leptin/saline injection. Loading was normalized using GAPDH and densitometry was performed using ImageJ software. Oneway ANOVA was used to analyze the leptin and saline-treated groups, ${ }^{* *} p<0.01$. (I) Quantitative results of pSTAT3 positive neurons after saline/leptin treatment. Data are expressed as the mean \pm SEM and the differences between the two groups were analyzed with Student's t-test. $* p<0.05, * * p<0.01$. 
after leptin administration, and this effect was significantly reduced in HFD-F1 (Figure 5G, 5H). These results reveal that HFD over diet during pregnancy in female rats tempts substantial leptin resistance in their male progenies.

\section{DISCUSSION}

The current results declared that HFD over intake during pregnancy in female rats could cause profligate weight gain and obesity in male offspring. This obese phenotype could be conceded into their second filial generation. Pups from HFD fed mother during pregnancy exhibited hyperphagia and increased body fat. Besides, offspring also showed significant alterations in hypothalamic leptin actions that might describe the deceptive leptin resistance.

Our results confirm that NPY and SOCS3 mRNA levels were higher in the HFD-F1, while POMC and $\mathrm{ObRb}$ mRNA levels were remains unchanged. Data from previous investigations disclosed that NPY level is higher in obese rats [24]. A study revealed that central NPY mRNA levels are high in some obesity models, like after temporary nutritional scarcity [25], lasting calories restriction [26], heavy exercise [27], and seasonal hyperphagia before hibernation [28]. These observations indicated that HFD feeding increased the NPY mRNA levels in the hypothalamus. SOCS3 has been suggested to cause defective leptin signaling in the Arc of HFD mice [29]. The heterozygous SOCS3-deficient mouse was more sensitive to the weight-reducing effects of leptin and was resistant to the development of diet-induced obesity [30]. Moreover, using an SOCS3 deficient mouse, Mori et al. showed that leptin-induced POMC level was increased in SOCS3 deficient mice than in wild-type mice [31]. These data designate that leptin-induced SOCS3 is a negative regulator of pSTAT3 signaling in the Arc. Data from previous research on mice by Pablo JE et al. presented that neither POMC mRNA expression nor ObRb expression in Arc was significantly different between HFD-induced obese mice and normal diet mice [32]. Our current results displayed that ObRb mRNA and POMC mRNA expression levels were not different between Chow-F1 and HFD-F1. These results agree with some studies in male mice fed with HFD [29, 33]. Sahu et al. indicated that $\mathrm{ObRb}$ expression in rats remained unchanged despite adenovirus-mediated hyperleptinaemia [33]. From all these observations, we conclude that excessive activity of SOCS3 is the potential mechanism for the leptin resistance in HFD-F1.

Our results revealed that high TG levels during pregnancy might induce chronically elevated leptin levels in offspring. It has been shown that TGs suppressed leptin passage through BBB and this blockade could be the reason for peripheral leptin sensitivity [34]. Adipose tissue release leptin into circulation and transported across BBB to the brain [35]. Their leptin binds to its receptor located in the Arc (Figure 6). Saturable transporter carries leptin across the BBB and defective transport may lead receptor errors and deteriorates with the increasing obesity [36]. The affinity of serum leptin levels and cerebrospinal fluid in obese humans [37] indicates that impaired BBB transport might account for overall leptin resistance than the receptor defects [9]. Data from clinical and animals studies showed that these metabolites were markedly elevated by both acute and chronic HFD situations [38]. Another study indicated that TG hydrolysis caused the release of fatty acids, which could modulate hypothalamic peptide expression [39]. It has been reported that hypothalamic injection of NPY increased TG levels [40]. These investigations showed that NPY neurons and cell bodies interact with peripheral metabolites via the hypothalamus.

Though HFD offspring from obese mother grew earlier than control pups and rapid weight gain after birth, observed in the present study, is because of metabolic remodeling of neuronal feeding circuits during pregnancy, which can further arouse food ingestion and increased body mass [41]. Because overfeeding plays a vital protagonist in obesity endemics [42]; therefore, we examined food intake in the F1 generation when the offspring were placed on standard chow diets.

Hypothalamus contains two sets of first-order neurons which are considered the best leptin-responsive neurons in the brain [43]. The neurons coexpressing NPY and Agouti-related peptide (AgRP), and neurons coexpressing POMC and cocaine and amphetamine-related transcript (CART). The former stimulate food intake while the latter repress it. Both sets of neurons extend their projections in Arc to second-order neurons, melanocortin 4 receptor (MC4R) and other areas in the brain (Figure 7). NPY/AgRP neurons are negatively regulated by leptin (Figure 6), and fasting boosts the expression of NPY and AgRP $[43,44]$. The study showed that deletion of AgRP neurons in mice triggered increased energy consumption and become mildly lean in late life [45]. In recent, NPY/ AgRP neurons were ablated postnatally, using different genetic approaches, although the deletion of neurons in each study was contrasted noticeably [46]. The message was a clear loss of NPY/AgRP neurons in adult life led to severe fat deposition. NPY connection with leptin has been a presently debatable point in appetite research. NPY act through G protein-coupled receptor, named (Y1-Y5). Earlier data recognized that $\mathrm{Y} 1$ and $\mathrm{Y} 5$ are more effective receptors expressed in hypothalamus regulating NPY neurons in response to appetite signals [47]. It has been reported that Arc NPY expression is decreased by leptin injection [48]. Previous observations also showed that leptin hyperpolarized NPY neurons in the hypothalamus and block their neuronal signaling in Arc [49]. A study revealed that orexin, a hormone released by adipocytes effect Arc through neuronal projection from the lateral hypothalamic area, activates NPY neurons [50]. Therefore, 
our data indicate that HFD-F1 offspring had increased number of NPY positive neurons in the hypothalamus and increased leptin levels. However, the increased level of leptin is due to leptin resistance in HFD-F1 offspring. These results clarify that obese mother and lactation has an adverse effect on energy consumption and metabolic complication in next generation.

Earlier observations confirmed that energy homeostasis required STAT3 expression on NPY neurons in Arc [51]. A study has confirmed that deletion of STAT3 from NPY neurons in mice leads to hyperphagia, and specific depletion of STAT3 in NPY neurons in hypothalamus resulted in increased NPY mRNA level, which led to obese phenotype [52]. Activation of STAT3 involves phosphorylation of tyrosine residue (Tyr 705). A study revealed that phosphorylation of STAT3 at Tyr 705 is most commonly mediated by JAKs, especially Janus tyrosine kinase 2 (JAK2) [53]. Previous data demonstrated that JAK2 and STAT3 pathways trigger leptin action [54, 55]. We assumed that obesity in HFD-F1 due to leptin resistance. Diet insufficiency usually results from a decrease in plasma leptin concentration, and low plasma leptin levels activate a chain of neuroendocrine signals to upsurge food ingestion [56]. Previous results indicated that phosphoinositol 3 kinase activates downstream targets, which in turn coordinates the STAT3 to activate NPY gene expression [57]. These investigations showed that STAT3 and NPY might involve in leptin resistance in obese animals. In the present study, pSTAT3 in the Arc was identified by IF and IHC after leptin/saline administration in both Chow-F1 and HFD-F1 groups. Leptin treatment in Chow-F1 significantly decreased food intake and increased number of pSTAT3-IR cell bodies in the Arc, suggesting Chow-F1 had a normal leptin signaling. There were no significant changes in the food consumption and pSTAT3-IR in saline treated HFD-F1 offspring, indicating that HFD-F1 is more susceptible to leptin. Thus, central leptin signaling in HFD-F1 must be rigorously decreased because they exhibited low sensitivity although leptin levels are high. From the present study, we conclude that HFD feeding during pregnancy has adverse outcomes in their male offspring via hypothalamic leptin resistance.

Our work indicates that HFD feeding during pregnancy in female rats may alter hypothalamic feeding networks and transform energy metabolism of their offspring. In the present study, we concentrated on

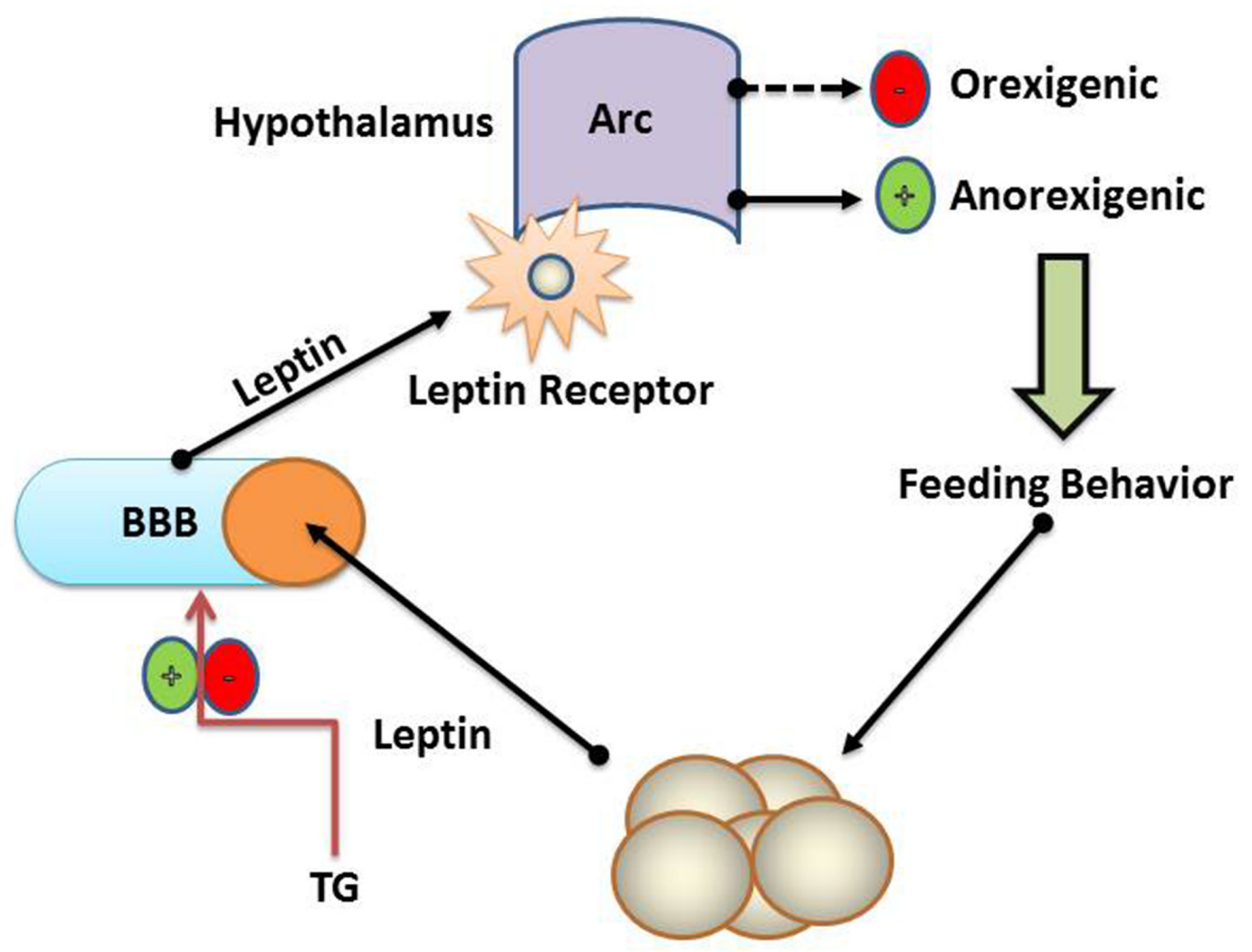

Fat Mass

Figure 6: Schematic representation of TG and blood brain barrier. Fat mass acts as a negative feedback loop for leptin. Increased fat mass results in increased levels of leptin in blood. TG controls the rate of passage of leptin across BBB. A saturable transport system at the BBB transports leptin into the hypothalamus' arcuate nucleus where leptin stimulates anorectics and inhibits orexigenic peptides, thus regulate feeding. TG and BBB have a critical role in the regulation of hypothalamic genes expression and control of feeding behaviors. 
maternal obesity. We concluded that metabolic alterations during pregnancy affect hypothalamic neurogenesis of their male offspring and developed leptin resistance. In a count of gene level investigations of hypothalamus concerning externals cues, the connection between parents and offspring is required. An explanation of these biological relations would help us to understand better the exact mechanism of human brain functions and development of neuronal circuits. Inhibition of SCOS3, MC4R direct stimulation may recover leptin resistance and to investigate whether similar hypothalamic changes occur in the second filial generation or not needs further research.

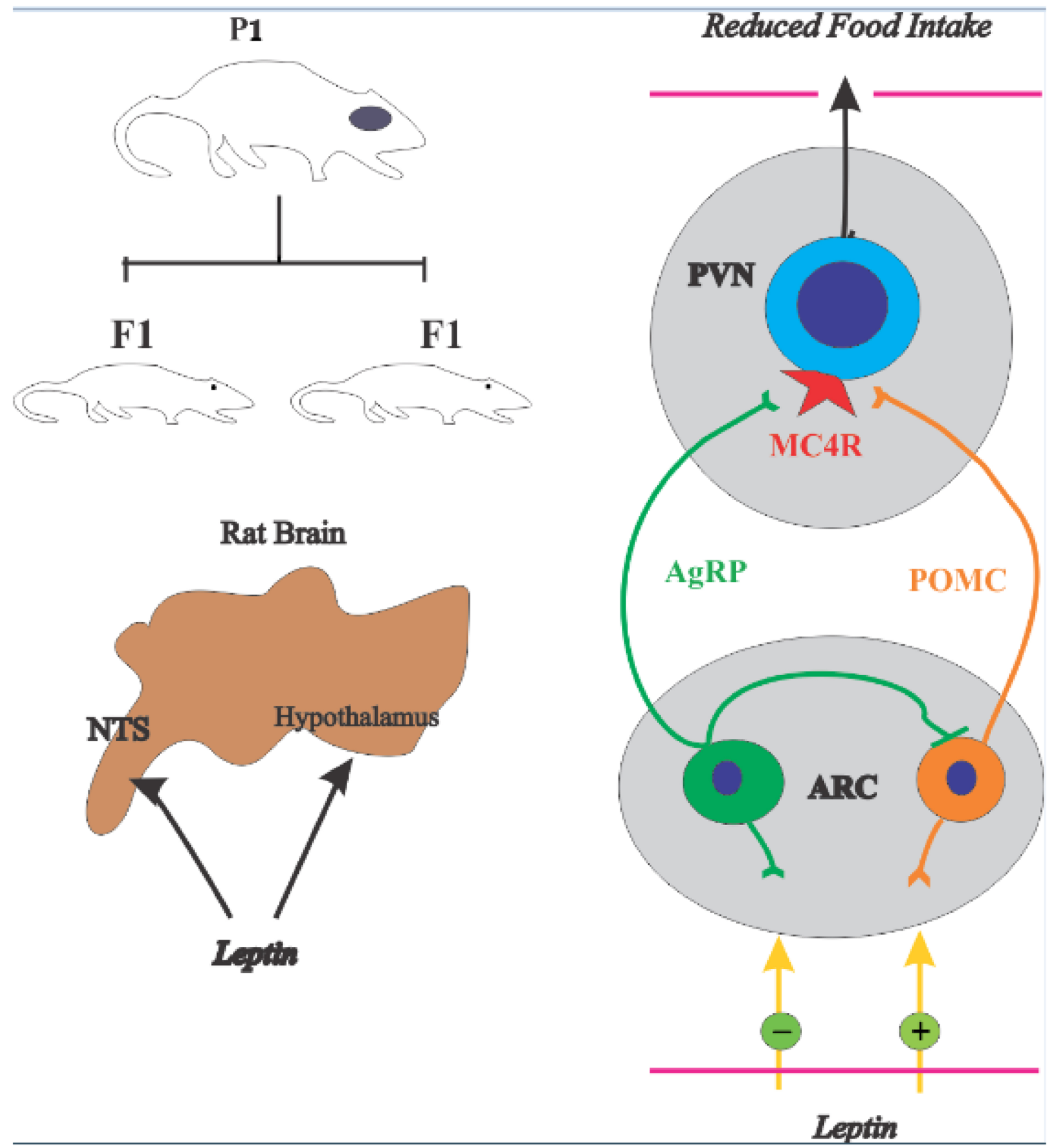

Figure 7: Control of food intake by a hypothalamic pathway. The hypothalamus receives and incorporates neural, metabolic, and hormonal signals to regulate energy homeostasis. Adipocyte-derived hormone leptin and the melanocortin pathway have a critical role in the control of food intake (A). AgRP, agouti-related protein; MC4R, melanocortin 4 receptor; POMC, pro-opiomelanocortin; PVN, paraventricular nucleus. 


\section{MATERIALS AND METHODS}

\section{Experimental model}

All animal treatments were performed in agreement with international ethical guidelines and the National Institutes of Health Guide for the Care and Use of Laboratory Animals. The experiments were directed with the approval of the Committee of Experimental Animal Administration School of Medicine, Zhejiang University. Six-week-old Sprague-Dawley (SD) rats weighing 140$160 \mathrm{~g}$ were purchased from the Shanghai Experimental Animal Center (Chinese Academy of Sciences, Shanghai, China) and housed (12: $12 \mathrm{~h}$ dark/light cycle) in the Zhejiang University Animal Center, Hangzhou, China. After acclimatization for 2 weeks, female rats were randomly allocated into two groups: normal control diet (chow, $\mathrm{n}=20$ ) or high-fat diet (HFD, $\mathrm{n}=20$ ) (Supplementary Table 1). Virgin female SD rats were mated with normal male SD rats at 10 weeks and pregnant females were fed chow or HFD from 8 weeks to delivery. Pregnancy-onset was assessed by the presence of a copulation plug after overnight mating (designated as day 0 (D0) of pregnancy). Maternal blood lipid levels were measured on D20 of pregnancy. Pups from HFD mothers were fostered by control females until they were weaned. Plasma was separated immediately after blood collection and stored at $-80^{\circ} \mathrm{C}$ for later analysis of leptin levels in serum and visceral fat (gonadal, retroperitoneal) and subcutaneous fat (inguinal) were collected under anesthesia (chloral hydrate $0.04 \mathrm{~g} / \mathrm{kg}$, i.p.) after 12 hours of fasting and weighed.

\section{Hematoxylin and eosin staining of white adipose tissue (WAT)}

White adipose tissues were post-fixed in $4 \%$ paraformaldehyde (PFA) for $48 \mathrm{~h}$, ethyl alcohol dehydrated and paraffin embedded. The tissues were sectioned on a microtome $(5 \mu \mathrm{m})$ and then stained with hematoxylin and eosin. The sections were photographed and assessed under a light microscope (BX51; Olympus, Tokyo, Japan). The size of the adipocytes was quantified using image $\mathrm{J}$, version 1.40 (NIH, Bethesda, MD, USA). In each rat, 80 random adipocytes from three sections were measured for cell size under 20x optical magnification and expressed as the mean adipocyte area.

\section{Hypothalamic mRNA extraction and qRT-PCR}

Total RNA from the hypothalamic enriched area the Arc (bregma -1.22 to $-2.54 \mathrm{~mm}$ ) and NTS (bregma -6.36 to $-7.76 \mathrm{~mm}$ ) was extracted from SD male offspring (4 weeks old) using TRIzol reagent (Life Technologies Corporation), according to the manufacturer's recommendations. RNA was quantified on a NanoDrop ND-2000 (Thermo Electron). $3 \mu \mathrm{g}$ of total RNA from each sample was reverse-transcribed to cDNA using random primers and a reverse transcription system (Takara Bio Inc., Otsu, Japan) in accordance with the manufacturer's instructions. After cDNA synthesis, quantitative real-time PCR was performed using iQTM SYBR Green Supermix (Bio-Rad, Hercules, CA, USA) in accordance with the manufacturer's instructions. The PCR conditions were one cycle of $95{ }^{\circ} \mathrm{C}$ for $3 \mathrm{~min}$, followed by 39 cycles of $95{ }^{\circ} \mathrm{C}$ for $10 \mathrm{~s}$ and $60{ }^{\circ} \mathrm{C}$ for $30 \mathrm{~s}$. PCR reactions were carried out in a $25 \mu \mathrm{l}$ of reaction buffer that included 12.5 $\mu \mathrm{l}$ of SYBR Green, $0.25 \mu \mathrm{l}$ of forwarding primer, 0.25

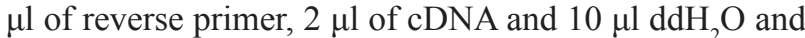
performed in triplicate for each sample in the Bio-Rad CFX96 Real-Time PCR system. The fluorescence intensity of each sample was measured at each temperature change to monitor amplification of the target gene. The quantity of target gene was normalized to the rat housekeeping gene glyceraldehyde-3-phosphate dehydrogenase (GAPDH). The primer sequences used for the PCR amplification were: GAPDH, 5'-GGATTTGGTCGTATTGGG-3' and 5'-GGAAGATGGTGATGGGATT-3'; NPY， 5'-CCGC CACGATGCTAGGTAAC-3'-and 5'-CAGCCAGAATG CCCAAACAC-3'; POMC, 5'-AGGCGACGGAAGAGAA AAGA-3' and 5'-AGATTGGAGGGACCCCTGT-3'; obRb, 5'-TTGTGTCCTACTGCTCGGAAC-3' and 5'-TG TTTCAGGCTTTTGGAAATTCAGT-3'; and SOCS3 5'-GCGGGCACCTTTCTTATCC-3', and 5'-TCCCCGAC TGGGTCTTGAC-3'.

\section{Immunofluorescence (IF)}

Ten HFD-F1 and Chow-F1 rats (4 weeks) from each group were sedated with $10 \%$ chloral hydrate $(0.5 \mathrm{ml} / 100$ g i.p.) and injected transcardially with saline followed by borate-buffered $4 \%$ paraformaldehyde $(4 \%$ PFA) $(\mathrm{pH}$ 7.4). The brains were removed and kept in $4 \%$ PFA for $48 \mathrm{~h}$. Super frost/plus microscope slides (Fisher) slide fixed sections were washed for several hours in PBS and then deparaffinized with xylene. Thereafter, the sections were incubated in PBS containing $1 \% \mathrm{H}_{2} \mathrm{O}_{2}$ for $10 \mathrm{~min}$ followed by 1 -hour incubation in blocking solution $(10 \%$ goat serum) and then incubated with the rabbit anti-NPY (Cat no. D7Y5A; Cell Signaling Technology, lnc; dilution 1:1000) antibody at $4-{ }^{\circ} \mathrm{C}$ overnight. After washing, a biotinylated secondary antibody Rhodamine Red-X goat anti-rabbit (Cat. no 1702286, Molecular Probe, Eugene, Oregon) and $\mathrm{ABC}$-elite solution (1:500 diluted in $0.1 \mathrm{M}$ PBS, for 1 hour) were used. DAPI (4',6-Diamidino-2Phenylindole, Dihydrochloride, Cat. No. D1306, ThermoScientific, Inc, US) was used as the chromogen. Finally, Slides were air dried, cover slipped with DPX medium mountant. The sections were photographed and assessed under a Carl Zeiss-800 confocal microscope (BadenWurttemberg, Germany). Data are presented as an average number of NPY positive cells per section from three Arc and NTS sections in each animal. Control sections for the 
single immunofluorescent procedure included omission of the primary antibody from the immunostaining protocol, which resulted in a complete absence of staining for the corresponding antigen.

\section{Leptin sensitivity}

To assess the differences in the anorexigenic effect of leptin between HFD-F1 and Chow-F1, the rats (4 weeks old) were fasted for $20.00 \mathrm{~h}$ on P29 to $08.00 \mathrm{~h}$ on day30, and then injected with saline or leptin $(2 \mu \mathrm{g} / \mathrm{g}$ body weight, i.p.) at $08.00 \mathrm{~h}$ on P30 [23]. Immediately after the injection, the food was given, and the consumption of the food was measured at 1, 2, 6 and $12 \mathrm{~h}$ after injection. Some rats were killed at $1 \mathrm{~h}$ after injection (leptin/saline) for pSTAT3 IF. The detailed protocol for hypothalamic IF analysis is as described above. The rabbit anti-pSTAT3 antibody (Cat no. D155018; BBI Life Sciences, Sangon Biotech, Shanghai, China; dilution 1:500) was used in the present study. The pSTAT3 was visualized with Alexa flour 488 conjugated streptavidin (Cat no. 1812166, Molecular Probe, Eugene, Oregon) with DAPI as a chromogen. Slides were air dried and cover slipped with DPX medium mountant. The data are presented as the mean number of p-STAT3 positive cells per section from three Arc sections in each animal. Photomicrographs were taken by Carl Zeiss- 800 confocal microscope and analyzed by image-j software (National Institutes of Health, Bethesda, MD, USA).

\section{Immunohistochemistry of hypothalamic NPY and PSTAT3}

Chow-F1 and HFD-F1 offspring ( $\mathrm{n}=8$, each group) were killed by anesthesia and transcardially perfused with saline followed by $4 \%$ PFA. The brains were excised and placed in ice-cold 4\% PFA for $4 \mathrm{~h}$ and then in $20 \%$ sucrose solution at $4 \mathrm{C}^{\circ}$ overnight. For the detection of NPY immunoreactivity, 5 um of hypothalamic sections were processed for IHC. Sections were blocked in 20 $\%$ goat serum to reduced nonspecific binding. NPY was detected using rabbit anti-NPY (Cat no. D121051; BBI life sciences, Shanghai, China; dilution 1:1000). After washing, second antibody Anti-Neuropeptide Y IgG (Cat no. ab10980) was used. DAPI (4',6-Diamidino-2Phenylindole, Dihydrochloride, Cat. No. D1306, ThermoScientific, Inc, US) was used as the chromogen. For leptin resistance, Chow-F1 and HFD-F1 (n=6, 4 weeks), monitored for food intake and were challenged with leptin/saline administration ( $2 \mu \mathrm{g} / \mathrm{g}$, i.p). Food intake was measured at 1, 2, 6 and $12 \mathrm{~h}$ after injection. The following day offspring were killed and whole hypothalami were removed for pSTAT3 immunohistochemical analysis. A detailed protocol is as described above. The rabbit anti-pSTAT3 antibody (Cat no. 9145; Cell Signaling Technology, Beverly, MA, USA; dilution 1:500) was used in the present study. Donkey Anti-Rabbit IgG secondary antibody (1:1000, Jackson Immuno Research Laboratories, West Grove, PA) against pSTAT3. Tissue was treated with Elite ABC Kit (Vector Labs, Burlingame, CA) for $1 \mathrm{~h}$, and the signal developed by Histostain-plus DAB kit (Cat no. 85-9243; Invitrogen). The sections were photographed and assessed under a light microscope (BX51; Olympus).

\section{Western blots}

Total protein from Arc and NTS were extracted by homogenization in ice-cold radioimmunoprecipitation assay buffer (phosphate-buffered saline, 1\% NP40, 0.5\% sodium deoxycholate, $0.1 \%$ sodium dodecyl sulfate, 1 $\mathrm{mmol} / \mathrm{l}$ phenylmethylsulfonyl fluoride, aprotinin $5 \mu \mathrm{g} / \mathrm{ml}$, leupeptin $10 \mu \mathrm{g} / \mathrm{ml}$, pepstatin A $1 \mu \mathrm{g} / \mathrm{ml}$ and phosphatase inhibitors cocktail). Homogenates were centrifuged for $25 \mathrm{~min}$ at $14,000 \mathrm{~g}$, supernatants collected and extract normalized to total protein content. The protein concentration was measured by BCA protein assay reagent kit (Pierce, Rockford, IL, USA). Proteins were separated by $12 \%$ SDS-PAGE, transfer to nitrocellulose membrane (Bio-Rad, Hercules, CA, USA) and blots was blocked for 1 $\mathrm{h}$ in $5 \%$ milk. Blots were incubated with antibodies to NPY (ab91262), SCOCS3 (ab16030), POMC (ab94446), ObRb (ab5593) and pSTAT3 (ab5073) (Abcam, Cambridge, UK, $1: 1000)$ overnight at $4 \mathrm{C}^{\circ}$, and then incubated with their respective secondary antibody for one hour. Expression was normalized to GAPDH (CW bio CW0266A, Beijing, China, 1:1000) and protein intensities were determined and analyzed using Odyssey ${ }^{\circledR}$ Imager (LI-COR, Lincoln, NE, USA).

\section{Blood hormones and biochemical assays}

Blood samples were collected from the heart and allowed for $10 \mathrm{~min}$ at room temperature. After clotting centrifuge it for $5 \mathrm{~min}$ at $3000 \mathrm{~g}$, and stored the serum at $-80^{\circ} \mathrm{C}$ until use. Serum leptin levels were measured by using commercial ELISA kit (Catalog no. F1532, Shanghai Westang Technology, China). The lowest detectable level and intraassay variation of leptin were $0.25 \mathrm{ng} / \mathrm{ml}$ and $7.6 \%$. Serum triglyceride, Glucose, total cholesterol, high-density lipoprotein and low-density lipoprotein were measured with a Biochemical Analyzer (Advia 2400 Chemistry System; Siemens, Munich, Germany).

\section{Statistical analysis}

All values are expressed as the mean \pm SEM. Graphpad prism, version 5.0 (GraphPad Software Inc., San Diego, CA, USA) was used for the statistical analysis. The body weight, body length, food intake and white adipose weight were analyzed using an unpaired Student's t-test. In the study of leptin sensitivity, two-way ANOVAs were conducted for the factors of treatment (leptin, saline) and groups (HFD-F1, Chow-F1). $P<0.05$ was considered statistically significant. 


\section{Author contributions}

Conceived and designed the experiments: T.U.R. Performed the experiments: T.U.R, K.U. Analyzed the data: L.U.J, Z.H.K, H.Y.P, T.T.W. Contributed reagents/ materials/analysis tools: M.X.G, Y.Z.Z, J.R, Y.C, X.Y.D. Wrote the paper: T.U.R, K.U, J.Z.S, H.F.H.

\section{ACKNOWLEDGMENTS}

This work is supported by the National Basic Research Program of China (2013CB967404 to H.F.H), the National Natural Science Foundation of China (No.81490742 and 31471405 to H.F.H, No.81300458 to T.T.W and No.31671569 to J.Z.S), the NSFC-CIHR Joint Health Research Program (No.8161101434 to H.F.H and No.81361128007 to J.Z.S), the NSFC-FRQS Joint Health Research Program (No.81361120246 to J.Z.S).

\section{CONFLICTS OF INTEREST}

The authors declare no conflicts of interest.

\section{REFERENCES}

1. Kopelman PG. Obesity as a medical problem. Nature. 2000; 404:635-643.

2. Mokdad AH, Ford ES, Bowman BA, Dietz WH, Vinicor F, Bales VS, Marks JS. Prevalence of obesity, diabetes, and obesity-related health risk factors, 2001. J Am Med Assoc. 2003; 289:76-79.

3. Ogden CL, Carroll MD, Curtin LR, McDowell MA, Tabak CJ, Flegal KM. Prevalence of overweight and obesity in the United States, 1999-2004. J Am Med Assoc. 2006; 295:1549-1555

4. Chen F, Wang Y, Shan X, Cheng H, Hou D, Zhao X, Wang T, Zhao D, Mi J. Association between childhood obesity and metabolic syndrome: evidence from a large sample of Chinese children and adolescents. PLoS One. 2012; 7:e47380.

5. Srinivasan M, Katewa SD, Palaniyappan A, Pandya JD, Patel MS. Maternal high-fat diet consumption results in fetal malprogramming predisposing to the onset of metabolic syndrome-like phenotype in adulthood. Am J Physiol Endocrinol Metab. 2006; 291:E792-E799.

6. Chang GQ, Gaysinskaya V, Karatayev O, Leibowitz SF. Maternal high-fat diet and fetal programming: increased proliferation of hypothalamic peptide-producing neurons that increase risk for overeating and obesity. J Neurosci. 2008; 28:12107-12119.

7. Balthasar N, Coppari R, McMinn J, Liu SM, Lee CE, Tang V, Kenny CD, McGovern RA, Chua SC Jr, Elmquist JK, Lowell BB. Leptin receptor signaling in POMC neurons is required for normal body weight homeostasis. Neuron. 2004; 42:983-991.
8. Coppari R, Ichinose M, Lee CE, Pullen AE, Kenny CD, McGovern RA, Tang V, Liu SM, Ludwig T, Chua SC Jr, Lowell BB, Elmquist JK. The hypothalamic arcuate nucleus: a key site for mediating leptin's effects on glucose homeostasis and locomotor activity. Cell Metab. 2005; 1:63-72.

9. Banks WA. Is obesity a disease of the blood-brain barrier? Physiological, pathological, and evolutionary considerations. Curr Pharm Des. 2003; 9:801-809.

10. Ferezou-Viala J, Roy AF, Serougne C, Gripois D, Parquet M, Bailleux V, Gertler A, Delplanque B, Djiane J, Riottot $\mathrm{M}$, Taouis M. Long-term consequences of maternal high-fat feeding on hypothalamic leptin sensitivity and diet-induced obesity in the offspring. Am J Physiol Regul Integr Comp Physiol. 2007; 293:R1056-R1062.

11. Muhlhausler BS, Adam CL, Findlay PA, Duffield JA, McMillen IC. Increased maternal nutrition alters development of the appetite-regulating network in the brain. FASEB J. 2006; 20:1257-1259.

12. Augustine RA, Ladyman SR, Grattan DR. From feeding one to feeding many: hormone-induced changes in bodyweight homeostasis during pregnancy. J Physiol. 2008; 586:387-397.

13. Zampieri TT, Ramos-Lobo AM, Furigo IC, Pedroso JA, Buonfiglio DC, Donato J Jr. SOCS3 deficiency in leptin receptor-expressing cells mitigates the development of pregnancy-induced metabolic changes. Mol Metab. 2015; 4:237-245.

14. Morton GJ, Meek TH, Schwartz MW. Neurobiology of food intake in health and disease. Nat Rev Neurosci. 2014; 15:367-378.

15. Trujillo ML, Spuch C, Carro E, Senaris R. Hyperphagia and central mechanisms for leptin resistance during pregnancy. Endocrinology. 2011; 152:1355-1365.

16. Nagaishi VS, Cardinali LI, Zampieri TT, Furigo IC, Metzger M, Donato J Jr. Possible crosstalk between leptin and prolactin during pregnancy. Neuroscience. 2014; 259:71-83.

17. Coll AP, Farooqi IS, O'Rahilly S. The hormonal control of food intake. Cell. 2007; 129:251-262.

18. Hayes MR, Skibicka KP, Leichner TM, Guarnieri DJ, DiLeone RJ, Bence KK, Grill HJ. Endogenous leptin signaling in the caudal nucleus tractus solitarius and area postrema is required for energy balance regulation. Cell Metab. 2016; 23:744.

19. Bouret SG, Simerly RB. Development of leptin-sensitive circuits. J Neuroendocrinol. 2007; 19:575-582.

20. Bouret SG, Bates SH, Chen S, Myers MG Jr, Simerly RB. Distinct roles for specific leptin receptor signals in the development of hypothalamic feeding circuits. J Neurosci. 2012; 32:1244-1252.

21. Wauman J, Tavernier J. Leptin receptor signaling: pathways to leptin resistance. Front Biosci (Landmark Ed). 2011; 16:2771-2793. 
22. Varela L, Horvath TL. Leptin and insulin pathways in POMC and AgRP neurons that modulate energy balance and glucose homeostasis. EMBO Rep. 2012; 13:1079-1086.

23. Enriori PJ, Evans AE, Sinnayah P, Jobst EE, TonelliLemos L, Billes SK, Glavas MM, Grayson BE, Perello M, Nillni EA, Grove KL, Cowley MA. Diet-induced obesity causes severe but reversible leptin resistance in arcuate melanocortin neurons. Cell Metab. 2007; 5:181-194.

24. Clark JT, Kalra PS, Crowley WR, Kalra SP. Neuropeptide $\mathrm{Y}$ and human pancreatic polypeptide stimulate feeding behavior in rats. Endocrinology. 1984; 115:427-429.

25. Grove KL, Chen P, Koegler FH, Schiffmaker A, Susan Smith M, Cameron JL. Fasting activates neuropeptide $\mathrm{Y}$ neurons in the arcuate nucleus and the paraventricular nucleus in the rhesus macaque. Brain Res Mol Brain Res. 2003; 113:133-138.

26. Bi S, Robinson BM, Moran TH. Acute food deprivation and chronic food restriction differentially affect hypothalamic NPY mRNA expression. Am J Physiol Regul Integr Comp Physiol. 2003; 285:R1030-R1036.

27. Chen JX, Zhao X, Yue GX, Wang ZF. Influence of acute and chronic treadmill exercise on rat plasma lactate and brain NPY, L-ENK, DYN A1-13. Cell Mol Neurobiol. 2007; 27:1-10.

28. Lakhdar-Ghazal N, Oukouchoud R, Pevet P. Seasonal variation in NPY immunoreactivity in the suprachiasmatic nucleus of the jerboa (Jaculus orientalis), a desert hibernator. Neurosci Lett. 1995; 193:49-52.

29. Munzberg H, Flier JS, Bjorbaek C. Region-specific leptin resistance within the hypothalamus of diet-induced obese mice. Endocrinology. 2004; 145:4880-4889.

30. Howard JK, Cave BJ, Oksanen LJ, Tzameli I, Bjorbaek C, Flier JS. Enhanced leptin sensitivity and attenuation of dietinduced obesity in mice with haploinsufficiency of Socs3. Nat Med. 2004; 10:734-738.

31. Mori H, Hanada R, Hanada $T$, Aki D, Mashima $R$, Nishinakamura $H$, Torisu $T$, Chien KR, Yasukawa $H$, Yoshimura A. Socs3 deficiency in the brain elevates leptin sensitivity and confers resistance to diet-induced obesity. Nat Med. 2004; 10:739-743.

32. Enriori PJ, Evans AE, Sinnayah P, Jobst EE, TonelliLemos L, Billes SK, Glavas MM, Grayson BE, Perello M, Nillni EA, Grove KL, Cowley MA. Diet-induced obesity causes severe but reversible leptin resistance in arcuate melanocortin neurons. Cell Metab. 2007; 5:181-194.

33. Sahu A, Nguyen L, O'Doherty RM. Nutritional regulation of hypothalamic leptin receptor gene expression is defective in diet-induced obesity. J Neuroendocrinol. 2002; 14:887-893.

34. Banks WA, Farr SA, Morley JE. The effects of high fat diets on the blood-brain barrier transport of leptin: failure or adaptation? Physiol Behav. 2006; 88:244-248.

35. Banks WA, Kastin AJ, Huang W, Jaspan JB, Maness LM. Leptin enters the brain by a saturable system independent of insulin. Peptides. 1996; 17:305-311.
36. Van Heek M, Compton DS, France CF, Tedesco RP, Fawzi AB, Graziano MP, Sybertz EJ, Strader CD, Davis HR Jr. Diet-induced obese mice develop peripheral, but not central, resistance to leptin. J Clin Invest. 1997; 99:385-390.

37. Caro JF, Kolaczynski JW, Nyce MR, Ohannesian JP, Opentanova I, Goldman WH, Lynn RB, Zhang PL, Sinha MK, Considine RV. Decreased cerebrospinal-fluid/serum leptin ratio in obesity: a possible mechanism for leptin resistance. Lancet. 1996; 348:159-161.

38. Buettner R, Newgard CB, Rhodes CJ, O'Doherty RM. Correction of diet-induced hyperglycemia, hyperinsulinemia, and skeletal muscle insulin resistance by moderate hyperleptinemia. Am J Physiol Endocrinol Metab. 2000; 278:E563-E569.

39. Gao S, Lane MD. Effect of the anorectic fatty acid synthase inhibitor $\mathrm{C} 75$ on neuronal activity in the hypothalamus and brainstem. Proc Natl Acad Sci U S A. 2003; 100:5628-5633.

40. Stafford JM, Yu F, Printz R, Hasty AH, Swift LL, Niswender KD. Central nervous system neuropeptide $\mathrm{Y}$ signaling modulates VLDL triglyceride secretion. Diabetes. 2008; 57:1482-1490.

41. Velloso LA, Schwartz MW. Altered hypothalamic function in diet-induced obesity. Int J Obes. 2011; 35:1455-1465.

42. Ellacott KL, Morton GJ, Woods SC, Tso P, Schwartz MW. Assessment of feeding behavior in laboratory mice. Cell Metab. 2010; 12:10-17.

43. Cone RD. Anatomy and regulation of the central melanocortin system. Nat Neurosci. 2005; 8:571-578.

44. Flier JS. Obesity wars: molecular progress confronts an expanding epidemic. Cell. 2004; 116:337-350.

45. Wortley KE, Anderson KD, Yasenchak J, Murphy A, Valenzuela D, Diano S, Yancopoulos GD, Wiegand SJ, Sleeman MW. Agouti-related protein-deficient mice display an age-related lean phenotype. Cell Metab. 2005; 2:421-427.

46. Flier JS. AgRP in energy balance: will the real AgRP please stand up? Cell Metab. 2006; 3:83-85.

47. Lecklin A, Lundell I, Paananen L, Wikberg JE, Mannisto PT, Larhammar D. Receptor subtypes Y1 and Y5 mediate neuropeptide $\mathrm{Y}$ induced feeding in the guinea-pig. Br J Pharmacol. 2002; 135:2029-2037.

48. Ahima RS, Prabakaran D, Mantzoros C, Qu D, Lowell B, Maratos-Flier E, Flier JS. Role of leptin in the neuroendocrine response to fasting. Nature. 1996; 382:250-252.

49. Spanswick D, Smith MA, Groppi VE, Logan SD, Ashford ML. Leptin inhibits hypothalamic neurons by activation of ATP-sensitive potassium channels. Nature. 1997; 390:521-525.

50. Burdakov D, Liss B, Ashcroft FM. Orexin excites GABAergic neurons of the arcuate nucleus by activating the sodiumcalcium exchanger. J Neurosci. 2003; 23:4951-4957.

51. Gong L, Yao F, Hockman K, Heng HH, Morton GJ, Takeda K, Akira S, Low MJ, Rubinstein M, MacKenzie RG. Signal transducer and activator of transcription-3 is required in 
hypothalamic agouti-related protein/neuropeptide Y neurons for normal energy homeostasis. Endocrinology. 2008; 149:3346-3354.

52. Chu SC, Chen PN, Hsieh YS, Yu CH, Lin MH, Lin YH, Kuo DY. Involvement of hypothalamic PI3K-STAT3 signalling in regulating appetite suppression mediated by amphetamine. Br J Pharmacol. 2014; 171:3223-3233.

53. Wen Z, Zhong Z, Darnell JE Jr. Maximal activation of transcription by Stat1 and Stat 3 requires both tyrosine and serine phosphorylation. Cell. 1995; 82:241-250.

54. Jiang L, Li Z, Rui L. Leptin stimulates both JAK2dependent and JAK2-independent signaling pathways. J Biol Chem. 2008; 283:28066-28073.
55. Frontini A, Bertolotti P, Tonello C, Valerio A, Nisoli E, Cinti S, Giordano A. Leptin-dependent STAT3 phosphorylation in postnatal mouse hypothalamus. Brain Res. 2008; 1215:105-115.

56. Ahima RS. Leptin and the neuroendocrinology of fasting. Front Horm Res. 2000; 26:42-56.

57. Roman EA, Reis D, Romanatto T, Maimoni D, Ferreira EA, Santos GA, Torsoni AS, Velloso LA, Torsoni MA. Central leptin action improves skeletal muscle AKT, AMPK, and PGC1 alpha activation by hypothalamic PI3K-dependent mechanism. Mol Cell Endocrinol. 2010; 314:62-69. 